\title{
Mamografi Dan Ultrasonografi Buah Dada (Malay Version)
}

\author{
Uqbah Iqbal* \\ School of History, Politics and Strategy, Faculty of Social Sciences and Humanities, Malaysia
}

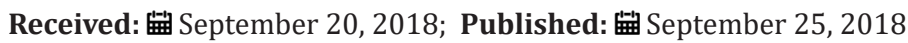

*Corresponding author: Uqbah Iqbal, School of History, Politics and Strategy, Faculty of Social Sciences and Humanities, UKM 43650, BangiSelangor, Malaysia

\section{Opinion}

Written by Mohd. Hamim Rajikin, knowledge about the human body is not only interesting but also important as it is necessary to understand various diseases. Many people now understand the complexities outside of themselves but many do not know how they themselves work. By knowing how complex the human body is as a biological engine, we will certainly appreciate the creator's greatness. Books that contain basic information about the functioning of human organs are written in simple language styles and the use of minimal scientific terms. Every description of an organ is accompanied by a diagram. As such, this book is appropriate for general reading, and those who do not have basic science at secondary level can understand it. This book will also be used as an additional reading book for those who are on preuniversity courses, physiotherapists, therapists, nursing and other paramedics.

Abdomen is a body space located between the thorax and the pelvis. A muscle layer called the diaphragm separates the chest from the abdomen. Abdomen contains organs that play a role in digestion and excretion. These organs include gaster, intestine, kidneys, liver, gallbladder, pancreas, spleen, appendix and bladder. In the abdomen, it also contains ovaries and uterus. All these organs mentioned will be explained in the relevant titles in this book. The adrenal glands are located on both kidneys, approximately as much as fingertip and weighing only $5 \mathrm{~g}$. But the task is great as it produces about 30-50 steroid compounds, which are similar hormones that can only be constructed by the vast expanse of chemical plants. However, the most important hormone is cortisol, a glucocorticoid and aldosterone, a mineralocorticoid. The release of cortisol is controlled by the adrenocorticotrophic hormone from the pituitary. Cortisol is important to hold or control inflammation in the body. Aldosteron also regulates the balance of salt in the body. Although these substances are synthesized in small amounts of about 30 mg a day it plays an important role in human life. If this gland is discarded, a person will experience low blood pressure and can die within a day or two, unless it is given an artificial mineralocorticoid hormone. Instead, if the gland is too active during the child's stage, adult nature; his voice became a jerk, his beard and his shoulders were bore and his sex organs grew up in adults. Apart from that, the long bones of the bones are supposed to remain open and soft until the perfect maturity is reached, closing quickly, making the growth stunted.

The adrenal glands are made up of two layers. The outer layer is the cortex and the inner layer is known as the medulla. All the hormones described above are found in the cortex. The adrenal part has a distinctive feature; it is a hotline to the brain. If someone is emotionally, for example, in fear, medula gets information instantly. As a result, two hormones, adrenaline and noradrenaline are released into the bloodstream. Both of these hormones can provide a person with an opponent or run activity. In addition his heart also releases sugar into blood circulation. These hormones cause the blood vessels to construct so that the person is pale while the blood is heavily streamed to the muscles, especially in the limbs to allow the members to work. The person's heart rate increases and his blood pressure increases. Digestion of food at this time becomes sluggish because the person does not have to think about food during this emergency. All these changes take place in just a few seconds and this makes the person either run faster or jumps up and lifts things that are heavier than normal, or any activity that is appropriate to the form of anxiety it encounters. The appendix is a dead-end, $7-12 \mathrm{~cm}$ long, located on the right side of the abdomen. The appendix is a branch of sekum which ends of the dead, while the sekum is part of the colon to the colon. The appendicitis function is unknown, but in case of infection or inflammation it has appendicitis. 

(C) This work is licensed under Creative

To Submit Your Article Click Here: Submit Article

DOI: $10.32474 /$ LOJMS.2018.01.000125

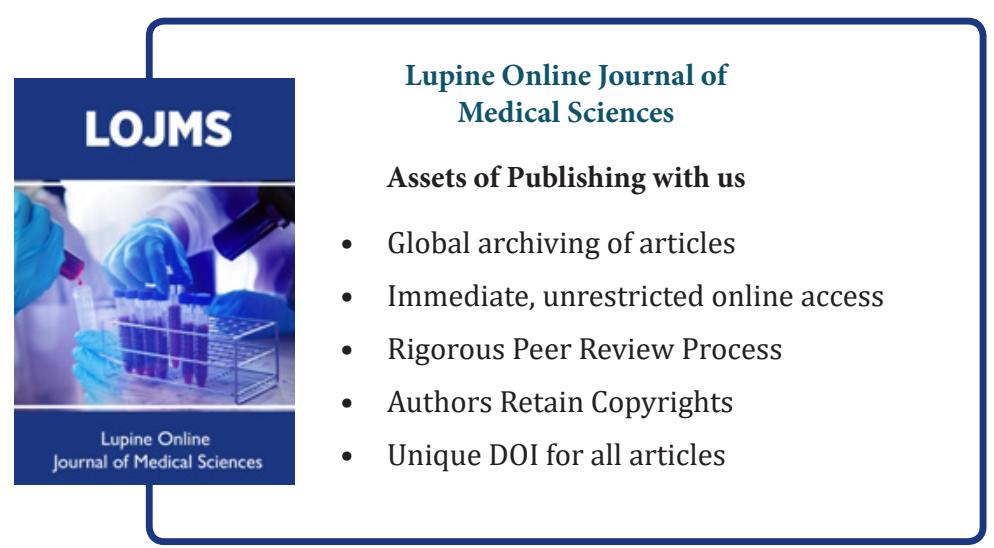

